\title{
Assessing the age specificity of infection fatality rates for COVID-19: systematic review, meta-analysis, and public policy implications
}

\author{
Andrew T. Levin ${ }^{1,2,3} \cdot$ William P. Hanage ${ }^{4} \cdot$ Nana Owusu-Boaitey $^{7} \cdot$ Kensington B. Cochran $^{1} \cdot$ Seamus P. Walsh $^{1}$. \\ Gideon Meyerowitz-Katz ${ }^{5,6}$ (I)
}

Received: 5 October 2020 / Accepted: 10 November 2020 / Published online: 8 December 2020

(c) The Author(s) 2020

\begin{abstract}
Determine age-specific infection fatality rates for COVID-19 to inform public health policies and communications that help protect vulnerable age groups. Studies of COVID-19 prevalence were collected by conducting an online search of published articles, preprints, and government reports that were publicly disseminated prior to 18 September 2020 . The systematic review encompassed 113 studies, of which 27 studies (covering 34 geographical locations) satisfied the inclusion criteria and were included in the meta-analysis. Age-specific IFRs were computed using the prevalence data in conjunction with reported fatalities 4 weeks after the midpoint date of the study, reflecting typical lags in fatalities and reporting. Meta-regression procedures in Stata were used to analyze the infection fatality rate (IFR) by age. Our analysis finds a exponential relationship between age and IFR for COVID-19. The estimated age-specific IFR is very low for children and younger adults (e.g., $0.002 \%$ at age 10 and $0.01 \%$ at age 25 ) but increases progressively to $0.4 \%$ at age $55,1.4 \%$ at age $65,4.6 \%$ at age 75 , and $15 \%$ at age 85 . Moreover, our results indicate that about $90 \%$ of the variation in population IFR across geographical locations reflects differences in the age composition of the population and the extent to which relatively vulnerable age groups were exposed to the virus. These results indicate that COVID-19 is hazardous not only for the elderly but also for middle-aged adults, for whom the infection fatality rate is two orders of magnitude greater than the annualized risk of a fatal automobile accident and far more dangerous than seasonal influenza. Moreover, the overall IFR for COVID-19 should not be viewed as a fixed parameter but as intrinsically linked to the age-specific pattern of infections. Consequently, public health measures to mitigate infections in older adults could substantially decrease total deaths.
\end{abstract}

Keywords COVID-19 $\cdot$ SARS-CoV-2 $\cdot$ Infection-fatality ratio $\cdot$ Infection-fatality rate $\cdot$ Systematicreview $\cdot$ Meta-regression

Electronic supplementary material The online version of this article (https://doi.org/10.1007/s10654-020-00698-1) contains supplementary material, which is available to authorized users.

Gideon Meyerowitz-Katz

gideon.meyerowitzkatz@health.nsw.gov.au

1 Dartmouth College, Hanover, USA

2 National Bureau for Economic Research, Cambridge, USA

3 Centre for Economic Policy Research, London, United Kingdom

4 Harvard T.H. Chan School of Public Health, Boston, USA

5 University of Wollongong, Wollongong, Australia

6 Western Sydney Local Health District, PO Box 792, Seven Hills, NSW 2147, Australia

7 Case Western Reserve University School of Medicine, Cleveland, USA

\section{Introduction}

Since the onset of the COVID-19 pandemic in winter 2020, it has been evident that the severity of the disease varies markedly across infected individuals [1]. Some remain asymptomatic throughout the course of infection or experience only mild symptoms such as headache or ageusia, whereas others experience much more severe illness, hospitalization, or even death [2]. Thus, official case reporting may tend to encompass a high fraction of severe cases but only a small fraction of asymptomatic or mildly symptomatic cases [3]. Moreover, the availability of live virus tests has varied significantly across locations and over time, and the deployment of such tests may differ markedly across demographic groups.

Consequently, assessments of the case fatality rate $(C F R)$, the ratio of deaths to reported cases, are fraught with 
pitfalls in gauging the severity of COVID-19. For example, early case reports from Wuhan noted a preponderance of older people among hospital admissions and a high CFR [4]. Subsequent studies have documented that children and young adults tend to exhibit fewer and milder symptoms and a far lower CFR than middle-aged and older adults $[5,6]$. Nonetheless, the link between age and severity of COVID19 infections has remained unclear for the reasons noted above.

To provide more accurate assessments of the spread of COVID-19, researchers have conducted seroprevalence studies in numerous locations [7, 8]. Such studies analyze samples of serum to detect antibodies in those infected with SARS-CoV-2, the virus that causes COVID-19. Estimates of prevalence (which includes asymptomatic and mildly symptomatic infections) can be used to estimate the infection fatality rate (IFR), the ratio of fatalities to total infections, thereby facilitating the identification of vulnerable segments of the population and informing key policy decisions aimed at mitigating the consequences of the pandemic [9].

For example, as shown in Table 1, the New York Department of Health conducted a large-scale seroprevalence study and estimated about 1.6 million SARS-CoV-2 infections among the 8 million residents of New York City [10]. However, only one-tenth of those infections were captured in reported COVID-19 cases, about one-fourth of which required hospitalization, and a substantial fraction of cases had fatal outcomes [11]. All told, COVID-19 fatalities in NYC represented a tenth of reported cases but only onehundredth of all SARS-CoV-2 infections.

Nonetheless, divergences in study design and reporting have hampered comparisons of seroprevalence and IFRs across locations and demographic groups. For example, a

Table 1 COVID-19 in New York City during spring 2020

\begin{tabular}{lll}
\hline & Number & $\begin{array}{l}\text { Share of } \\
\text { infections } \\
(\%)\end{array}$ \\
\hline NYC residents & 8 million & NA \\
Estimated infections & 1.6 million & 100 \\
Symptomatic infections & 1.1 million & 65 \\
Reported cases & 220 thousand & 12 \\
Hospitalized patients & 55 thousand & 3 \\
Fatal outcomes & 17 thousand & 1 \\
\hline
\end{tabular}

This table reports on the characteristics of COVID-19 infections in New York City (NYC). Infection prevalence was estimated by the New York Department of Health using samples collected on April 19-28, 2020 [10]. The ratio of symptomatic to total infections reflects a recent assessment by the U.S. Center for Disease Control and Prevention [38]. The number of cases, hospitalized patients, and fatal outcomes is reported by the NYC Department of Health; as of May 22 (4 weeks after the midpoint of the seroprevalence study), NYC had 17,336 confirmed COVID-19 deaths [11] number of studies have analyzed a representative sample of the general population, while other studies have made use of "convenience samples" of residual sera collected for other purposes (such as laboratory tests or blood donations) [12-14]. Some studies have simply reported results for raw prevalence (the fraction of seropositive results), whereas other studies have reported results adjusted for antibody test characteristics (sensitivity and specificity).

While the NYC data indicate a population IFR of about $1 \%$, seroprevalence estimates from other locations have yielded a wide array of population IFR estimates, ranging from about $0.6 \%$ in Geneva to levels exceeding $2 \%$ in northern Italy. Such estimates have fueled intense controversy about the severity of COVID-19 and the appropriate design of public health measures to contain it, which in turn hinges on whether the hazards of this disease are mostly limited to the elderly and infirm. Indeed, a recent meta-analysis noted the high degree of heterogeneity across aggregate estimates of IFR and concluded that research on age-stratified IFR is "urgently needed to inform policymaking." [15]

This paper reports on a systematic review and metaanalysis of age-specific IFRs for COVID-19. We specifically consider the hypothesis that the observed variation in IFR across locations may primarily reflect the age specificity of COVID-19 infections and fatalities. Based on these findings, we are able to assess and contextualize the severity of COVID-19 and examine how age-specific prevalence affects the population IFR and the total incidence of fatalities.

\section{Methodology}

To perform the present meta-analysis, we collected published papers and preprints on the seroprevalence and/or infection fatality rate of COVID-19 that were publicly disseminated prior to 18 September 2020. As described in Supplementary Appendix B, we systematically performed online searches in MedRxiv, Medline, PubMed, Google Scholar, and EMBASE, and we identified other studies listed in reports by government institutions such as the U.K. Parliament Office [16]. Data was extracted from studies by three authors and verified prior to inclusion.

We restricted our meta-analysis to studies of advanced economies, based on current membership in the Organization for Economic Cooperation and Development (OECD), in light of the distinct challenges of health care provision and reporting of fatalities in developing economies [17]. We also excluded studies aimed at measuring prevalence in specific groups such as health care workers.

Our meta-analysis encompasses two distinct approaches for assessing the prevalence of.

COVID-19: (1) seroprevalence studies that test for antibodies produced in response to the virus, and (2) 
comprehensive tracing programs using extensive live-virus testing of everyone who has had contact with a potentially infected individual. Seroprevalence estimates are associated with uncertainty related to the sensitivity and specificity of the test method and the extent to which the sampling frame provides an accurate representation of prevalence in the general population; see Supplementary Appendix C. Prevalence measures from comprehensive tracing programs are associated with uncertainty about the extent of inclusion of infected individuals, especially those who are asymptomatic.

\section{Sampling frame}

To assess prevalence in the general population, a study should be specifically designed to utilize a random sample using standard survey procedures such as stratification and weighting by demographic characteristics. Other sampling frames may be useful for specific purposes such as sentinel surveillance but not well-suited for assessing prevalence due to substantial risk of systemic bias. Consequently, our metaanalysis excludes the following types of studies:

- Blood donors. Only a small fraction of blood donors are ages 60 and above- a fundamental limitation in assessing COVID-19 prevalence and IFRs for older age groups-and the social behavior of blood donors may be systematically different from their peers $[13,18]$. These concerns can be directly investigated by comparing alternative seroprevalence surveys of the same geographical location. As of early June, Public Health England (PHE) reported seroprevalence of $8.5 \%$ based on specimens from blood donors, whereas the U.K. Office of National Statistics (ONS) reported markedly lower seroprevalence of 5.4\% (CI: 4.3-6.5\%) based on its monitoring of a representative sample of the English population [19,20].

- Dialysis centers. Assessing seroprevalence of dialysis patients using residual sera collected at dialysis centers is crucial for gauging the infection risks faced by these individuals, of which a disproportionately high fraction tend to be underrepresented minorities. Nonetheless, the seroprevalence within this group may be markedly different from that of the general population. For example, a study of U.K. dialysis patients found seroprevalence of about $36 \%$, several times higher than that obtained using a very large random sample of the English population $[21,22]$. Similarly, a recent U.S. study found a seropositive rate of $34 \%$ for dialysis patients in New York state that was more than twice as high as the seroprevalence in a random sample of New York residents [10, 23].

- Hospitals and urgent care clinics. Estimates of seroprevalence among current medical patients are subject to substantial bias, as evident from a pair of studies conducted in Tokyo, Japan: One study found 41 positive cases among 1071 urgent care clinic patients, whereas the other study found only two confirmed positive results in a random sample of nearly 2000 Tokyo residents (seroprevalence estimates of $3.8 \%$ vs. $0.1 \%$ ) [24, 25].

- Active recruitment. Soliciting participants is particularly problematic in contexts of low prevalence, because seroprevalence can be markedly affected by a few individuals who volunteer due to concerns about prior exposure. For example, a Luxembourg study obtained positive antibody results for 35 out of 1807 participants, but nearly half of those individuals ( 15 of 35 ) had previously had a positive live virus test, were residing in a household with someone who had a confirmed positive test, or had direct contact with someone else who had been infected [26].

Our critical review has also underscored the pitfalls of seroprevalence studies based on "convenience samples" of residual sera collected for other purposes. For example, two studies assessed seroprevalence of Utah residents during spring 2020. The first study analyzed residual sera from two commercial laboratories and obtained a prevalence estimate of $2.2 \%$ (CI: $1.2-3.4 \%$ ), whereas the second study collected specimens from a representative sample and obtained a markedly lower prevalence estimate of $0.96 \%$ (CI: 0.4-1.8\%) $[27,28]$. In light of these issues, our meta-analysis includes residual serum studies but we flag such studies as having an elevated risk of bias.

\section{Comprehensive tracing programs}

Our meta-analysis incorporates data on COVID-19 prevalence and fatalities in countries that have consistently maintained comprehensive tracing programs since the early stages of the pandemic. Such a program was only feasible in places where public health officials could conduct repeated tests of potentially infected individuals and trace those whom they had direct contact. We identify such countries using a threshold of 300 for the ratio of cumulative tests to reported cases as of 30 April 2020, based on comparisons of prevalence estimates and reported cases in Czech Republic, Korea, and Iceland; see Supplementary Appendices D and E [29]. Studies of Iceland and Korea found that estimated prevalence was moderately higher than the number of reported cases, especially for younger age groups; hence we make corresponding adjustments for other countries with comprehensive tracing programs, and we identify these estimates as subject to an elevated risk of bias [30-32].

\section{Measurement of fatalities}

Accurately measuring total deaths is a substantial issue in assessing IFR due to time lags from onset of symptoms to death and from death to official reporting. Symptoms 
typically develop within 6 days after exposure but may develop as early as 2 days or as late as 14 days [1, 33]. More than $95 \%$ of symptomatic COVID patients have positive antibody ( $\operatorname{IgG}$ ) titres within 17-19 days of symptom onset, and those antibodies remain elevated over a sustained period [34-37]. The mean time interval from symptom onset to death is 15 days for ages 18-64 and 12 days for ages $65+$, with interquartile ranges of 9-24 days and 7-19 days, respectively, while the mean interval from date of death to the reporting of that person's death is about 7 days with an IQR of 2-19 days; thus, the upper bound of the 95\% confidence interval between symptom onset and reporting of fatalities is about 6 weeks (41 days) [38].

Figure 1 illustrates these findings in a hypothetical scenario where the pandemic was curtailed 2 weeks prior to the date of the seroprevalence study. This figure shows the results of a simulation calibrated to reflect the estimated distribution for time lags between symptom onset, death, and inclusion in official fatality reports. The histogram shows the frequency of deaths and reported fatalities associated with the infections that occurred on the last day prior to full containment. Consistent with the confidence intervals noted above, $95 \%$ of cumulative fatalities are reported within roughly 4 weeks of the date of the seroprevalence study.

As shown in Table 2, the precise timing of the count of cumulative fatalities is relatively innocuous in locations where the outbreak had been contained for more than a

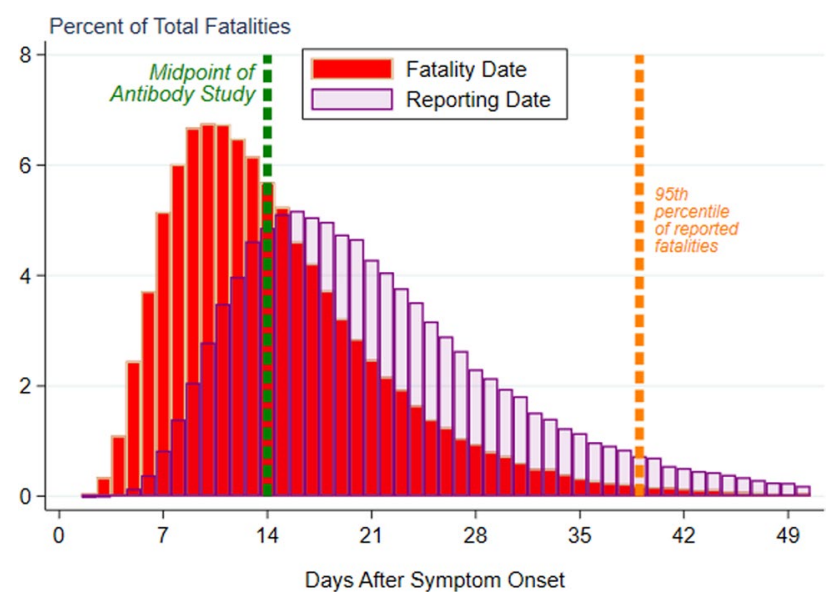

Fig. 1 Time lags in the incidence and reporting of COVID-19 fatalities. Note: This figure illustrates time lags in the incidence and reporting of COVID-19 fatalities using the results of a simulation calibrated to reflect the estimated distribution for time lags between symptom onset, death, and inclusion in official fatality reports [38]. As indicated by the vertical green line, this simulation assumes that the seroprevalence study was conducted two weeks after the pandemic was curtailed. The histogram shows the frequency of deaths and reported fatalities associated with the infections that occurred on the last day prior to full containment. As indicated by the orange vertical line, $95 \%$ of cumulative fatalities are reported within about 4 weeks after the midpoint date of the seroprevalence study month prior to the date of the seroprevalence study. By contrast, in instances where the outbreak had only recently been contained, the death count continued rising markedly for several more weeks after the midpoint of the seroprevalence study.

Therefore, we construct age-specific IFRs using the seroprevalence data in conjunction with cumulative fatalities 4 weeks after the midpoint date of each study; see Supplementary Appendix F. We have also conducted sensitivity analysis using cumulative fatalities 5 weeks after the midpoint date, and we flag studies as having an elevated risk of bias if the change in cumulative fatalities between weeks 4 and 5 exceeds $10 \%$.

By contrast, matching prevalence estimates with subsequent fatalities is not feasible if a seroprevalence study was conducted in the midst of an accelerating outbreak. Therefore, our meta-analysis excludes seroprevalence studies for which the change in cumulative fatalities from week 0 to week 4 exceeds $200 \%$.

\section{Metaregression procedure}

To analyze IFR by age, we use meta-regression with random effects, using the meta regress procedure in Stata v16 $[39,40]$. In the metaregression, the dependent variable is the IFR for a specific age group in a specific geographical location, and the explanatory variable is the median age of that particular age group. We used a random-effects procedures to allow for residual heterogeneity between studies and across age groups by assuming that these divergences are drawn from a Gaussian distribution.

To assess the robustness of the metaregression results, we conduct several forms of sensitivity analysis:

- Analyze whether the metaregression coefficients exhibit any significant differences across three broad age categories (ages 0-34, 35-59, and 60+ years);

- Analyze whether the results are sensitive to exclusion of the oldest age group in each location (e.g., ages $65+$ years), given that such groups may span a relatively wide age range and hence not fully capture their vulnerability to the virus;

- Conduct out-of-sample analysis using small-scale seroprevalence studies as well as studies not included in the metaregression due to overlapping geographical regions;

- Compare the actual population IFR in each location (based on estimated prevalence and confirmed deaths across all age groups) with the population IFR predicted by the metaregression (computed using the estimated prevalence and the predicted number of deaths within each reported age group). 
Finally, publication bias is assessed using Egger's regression and the trim-and-fill method.

\section{Results}

As shown in fig. 2, after an initial screening of 1146 studies, we reviewed the full texts of 113 studies, of which 54 studies were excluded due to lack of age-specific data on COVID-19 prevalence or fatalities [20, 24, 25, 41-91]. Seroprevalence estimates for two locations were excluded because the outbreak was still accelerating during the period when the specimens were being collected and from two other locations for which age-specific seroprevalence was not distinguishable from zero [27, 92-94]. Studies of non-representative samples were excluded as follows: 13 studies of blood donors; 5 studies of patients of hospitals, outpatient clinics, and dialysis centers; 4 studies with active recruitment of participants, and 6 narrow sample groups such as elementary schools [19, 23, 25, 26, 92, 95-117]. Supplementary Appendix H lists all excluded studies.

Consequently, our meta-analysis encompasses 27 studies of 34 geographical locations, of which 28 are included in our metaregression and 6 are used for out-of-sample analysis. The metaregression observations can be categorized into three distinct groups:

- Representative samples from studies of England, France, Ireland, Italy, Netherlands, Portugal, Spain, Geneva (Switzerland), and four U.S. locations (Atlanta, Indiana, New York, and Salt Lake City) [10, 22, 28, 118-127].

- Convenience samples from studies of Belgium, Sweden, Ontario (Canada), and eight U.S. locations (Connecticut, Louisiana, Miami, Minneapolis, Missouri, Philadelphia, San Francisco, and Seattle) [27, 128-130].

- Comprehensive tracing programs for Australia, Iceland, Korea, Lithuania, and New Zealand [131-135].

The metaregression includes results from the very large REACT-2 seroprevalence study of the English population [22]. Thus, to avoid pitfalls of nested or overlapping samples, two other somewhat smaller studies conducted by U.K. Biobank and the U.K. Office of National Statistics are not included in the metaregression but are instead used in outof-sample analysis of the metaregression results [20, 136]. Similarly, the metaregression includes two large-scale studies involving representative samples from three French provinces and from Salt Lake City, and hence two other studies using convenience samples from laboratories in France and in Utah are used in the out-of-sample analysis along with two other small-scale studies [27, 28, 137-139].

Data taken from included studies is shown in Supplementary Appendix I. Supplementary Appendix J assesses the risk of bias for each individual study. As indicated in Supplementary Appendix K, no publication bias was found using Egger's test $(p>0.10)$, and the trim-and-fill method produced the same estimate as the metaregression.

We obtain the following metaregression results:

$\log _{10}(I F R)=-3.27+0.0524 *$ age

(0.07) (0.0013)

where the standard error for each estimated coefficient is given in parentheses. These estimates are highly significant with t-statistics of -44.5 and 40.4 , respectively, and $p$-values below 0.0001 . The residual heterogeneity $\tau^{2}=0.071$ ( $p$-value $<0.0001)$ and $\mathrm{I}^{2}=97.0$, confirming that the random effects are essential for capturing unexplained variations across studies and age groups. The adjusted $\mathrm{R}^{2}$ is $94.7 \%$.

As noted above, the validity of this metaregression rests on the condition that the data are consistent with a Gaussian distribution. The validity of that assumption is evident in Fig. 3: Nearly all of the observations fall within the 95\% prediction interval of the metaregression, and the remainder are moderate outliers.

This specification of the metaregression also assumes that the intercept and slope parameters are stable across the entire age distribution. We have confirmed the validity of that assumption by estimating alternative specifications in which the parameters are allowed to differ between three distinct age categories (ages 0-34, 35-59, and 60+ years). The estimated parameters are similar across all three age categories, and the null hypothesis of parameter constancy is consistent with the metaregression data. We have also confirmed that the metaregression results are not sensitive to exclusion of open-ended top age groups. (See Supplementary Appendix L for details.)

Figure 4 depicts the exponential relationship between age and the level of IFR in percent, and Fig. 5 shows the corresponding forest plot. Evidently, the SARS-CoV-2 virus poses a substantial mortality risk for middle-aged adults and even higher risks for elderly people: The IFR is very low for children and young adults (e.g., $0.002 \%$ at age 10 and $0.01 \%$ at age 25 ) but rises to $0.4 \%$ at age 55 , $1.4 \%$ at age $65,4.6 \%$ at age $75,15 \%$ at age 85 , and exceeds $25 \%$ for ages 90 and above. These metaregression predictions are well aligned with the out-of-sample IFRs; see Supplementary Appendix M.

As shown in Fig. 6, population IFR (computed across all ages) ranges from about $0.5 \%$ in Salt Lake City and Geneva to $1.5 \%$ in Australia and England and 2.7\% in Italy. The metaregression results indicate that about $90 \%$ of the variation in population IFR across geographical locations reflects differences in the age composition of the population and the extent to which relatively vulnerable age groups were exposed to the virus. 
Fig. 2 Study selection (PRISMA flow diagram)

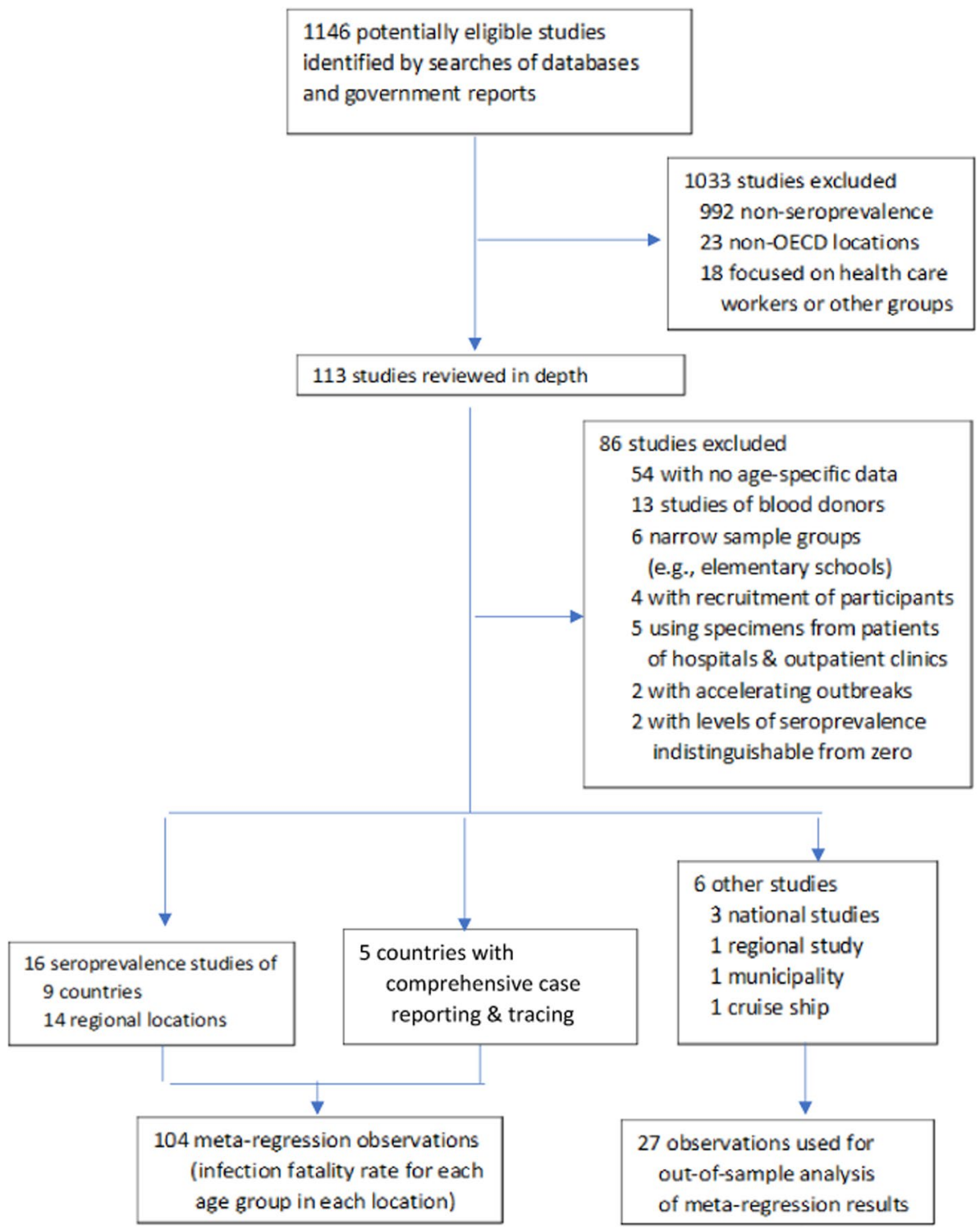

\section{Discussion}

The IFR is central to our understanding of the public health impact of the COVID-19 pandemic and the appropriate policies for mitigating those consequences. In the absence of effective therapies or vaccines, such policies will primarily involve non-pharmaceutical interventions (NPIs). NPIs may include relatively mild measures (such as prohibitions on large gatherings) or more draconian restrictions such as shelter-in-place edicts, popularly known as "lockdowns."

Unfortunately, public debate on these issues has been hampered by diverging assessments of the severity of COVID-19. For example, some early seroprevalence studies (using relatively small and non-representative samples, often in areas of low prevalence) yielded miniscule estimates of population IFR similar to those of seasonal influenza. Such estimates implied that strict NPIs would be completely irrational given the limited benefits and severe economic and social costs. With the dissemination of many more seroprevalence studies over recent months, a wide array of hypotheses have been mooted to explain the diverging implications for IFR, including regional variations in the quality of treatment or the extent of T-cell immunity to other betacoronaviruses.

By contrast, our critical review identifies the key characteristics of seroprevalence studies that can be used to provide reliable assessments of IFR. Indeed, once we focus on this group of studies (which includes nine national seroprevalence studies), our metaregression reveals a remarkably high degree of consistency in the implications for age-specific IFR. Moreover, our results indicate that most of the variation in population IFR across locations reflects differences in the extent to which vulnerable age groups were exposed to the virus. 
Table 2 Timing of reported fatalities for selected seroprevalence studies

\begin{tabular}{|c|c|c|c|c|c|}
\hline \multirow[t]{2}{*}{ Location } & \multicolumn{3}{|c|}{ Cumulative fatalities } & \multicolumn{2}{|l|}{ Change (\%) } \\
\hline & Study midpoint & 4 weeks later & 5 weeks later & Weeks $0-4$ & Weeks 4-5 \\
\hline \multicolumn{6}{|l|}{ Europe } \\
\hline Belgium & 6262 & 8843 & 9150 & 41 & 3 \\
\hline Geneva, Switzerland & 255 & 287 & 291 & 13 & 1 \\
\hline Spain & 26,834 & 27,136 & 28,324 & 1 & 4 \\
\hline Sweden & 2586 & 3831 & 3940 & 48 & 3 \\
\hline \multicolumn{6}{|l|}{$U S A$} \\
\hline Connecticut & 2257 & 3637 & 3686 & 61 & 1 \\
\hline Indiana & 932 & 1984 & 2142 & 113 & 8 \\
\hline Louisiana & 477 & 2012 & 2286 & 322 & 14 \\
\hline Miami & 513 & 1160 & 1290 & 126 & 11 \\
\hline Minneapolis & 393 & 964 & 1093 & 145 & 13 \\
\hline Missouri & 218 & 562 & 661 & 158 & 18 \\
\hline New York & 20,212 & 28,663 & 29,438 & 42 & 3 \\
\hline Philadelphia & 456 & 1509 & 1754 & 231 & 16 \\
\hline San Francisco & 265 & 424 & 449 & 60 & 6 \\
\hline Seattle & 536 & 732 & 775 & 37 & 6 \\
\hline Utah & 41 & 96 & 98 & 134 & 2 \\
\hline
\end{tabular}

This table shows data on confirmed COVID-19 deaths for 4 European locations and 11 U.S. locations where seroprevalence has been assessed [27, 124, 129, 163-165]. Sources of fatality data are given in Supplementary Appendix F. For each location, the second column shows cumulative fatalities from the onset of the pandemic until the midpoint date of that seroprevalence study, while the next two columns report cumulative deaths 4 and 5 weeks later, respectively. The last two columns show the percent change in cumulative fatalities over each specified time interval (weeks 0-4 and weeks 4-5, respectively)
One key implication of our findings is that the incidence of fatalities from a COVID-19 outbreak depends crucially on the age groups that are infected, which in turn reflects the age structure of that population and the extent to which public health measures limit the incidence of infections among vulnerable age groups [140]. Indeed, even if an outbreak is mainly concentrated among younger people, it may be very difficult to prevent the virus from spreading among older adults [141].

To gauge the benefits of age-stratified public health strategies for COVID-19, we have constructed two illustrative scenarios for the U.S. trajectory of infections and fatalities (see Supplementary Appendix N). Each scenario assumes that U.S. prevalence rises to a plateau of around $20 \%$ but with different patterns of age-specific prevalence. In particular, if prevalence becomes uniform across age groups, this analysis projects that total U.S. fatalities would rise to nearly 900 thousand and that population IFR would converge to around $1.3 \%$. By contrast, a scenario with relatively low incidence of new infections among vulnerable age groups would be associated with a much lower number of fatalities (about 350 thousand) and a correspondingly lower population IFR of about $0.5 \%$.

A further implication of our results is that the risks of infection to the middle aged cannot be neglected. This is important for pandemic management strategies that aim to avoid large influxes of patients to healthcare. Indeed, it is likely that an unmitigated outbreak among middle-aged and older adults could have severe consequences on the healthcare system.

Public health communications can be helpful for persuading individuals to take steps to mitigate the risk of infection for themselves as well as others with whom they have direct contact (family members, friends, and colleagues). For this purpose, it is helpful to contextualize the magnitude of agespecific IFRs for COVID-19 relative to annualized fatality rates for other routine activities; that annual timeframe reflects the premise that effective vaccines and/or treatments for COVID-19 would hopefully become widely available sometime within the next year or two.

In particular, Table 3 compares the age-specific IFRs from our meta-regression analysis to the annualized risks of fatal automobile accidents or other unintentional injuries in England and in the United States [142, 143]. For example, an English person aged 55-64 years who gets infected with SARS-CoV-2 faces a fatality risk that is more than 200 times higher than the annual risk of dying in a fatal car accident. These results also confirm that COVID-19 is far more deadly than seasonal flu; indeed, the World Health Organization indicates that seasonal influenza mortality is usually well below $0.1 \%$ unless access to health care is constrained [144]. (See Supplementary Appendix O for further details.) 


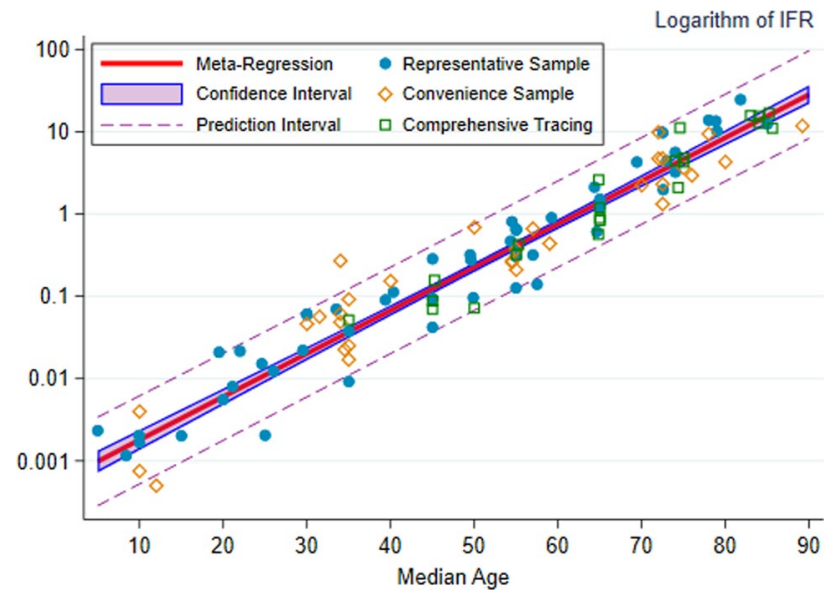

Fig. 3 The log-linear relationship between IFR and age. Note: Our metaregression indicates that the infection fatality rate (IFR) increases exponentially with age, and hence this figure uses a base10 logarithmic scale so that the relationship is evident across all ages from 5 to 95 years. Each marker denotes a specific metaregression observation, that is, the IFR for a particular age group in a particular location. The marker style reflects the type of observation: circles for observations from seroprevalence studies of representative samples, diamonds for seroprevalence studies of convenience samples, and squares for countries with comprehensive tracing programs. The red line denotes the metaregression estimate of IFR as a function of age, the shaded region depicts the $95 \%$ confidence interval for that estimate. The dashed lines denote the prediction interval (which includes random variations across studies and age groups), and almost all of the 108 metaregression observations lie within that interval.

Moreover, mortality from seasonal influenza outbreaks is mitigated by prior immunity and vaccinations, whereas that is not the case for SARS-CoV-2.

Our critical review highlights the benefits of assessing prevalence using large-scale studies of representative samples of the general population rather than convenience samples of blood donors or medical patients. Conducting such studies on an ongoing basis will enable public health officials to monitor changes in prevalence among vulnerable age groups and gauge the efficacy of public policy measures. Moreover, such studies enable researchers to assess the extent to which antibodies to SARS-CoV-2 may gradually diminish over time as well as the extent to which advances in treatment facilitate the reduction of age-specific IFRs.

Our critical review also underscores the importance of methodological issues in assessing IFR. For example, the raw prevalence results reported by a national study of Italy would imply a population IFR of about $2.3 \%$, whereas testadjusted prevalence implies a substantially higher IFR of $2.7 \%$. Likewise, a few recent studies have excluded all deaths occurring in nursing homes and retirement communities and have obtained estimates of population IFR that are markedly lower than our estimates based on all confirmed COVID-19 fatalities, whereas assessments of IFR based on measures

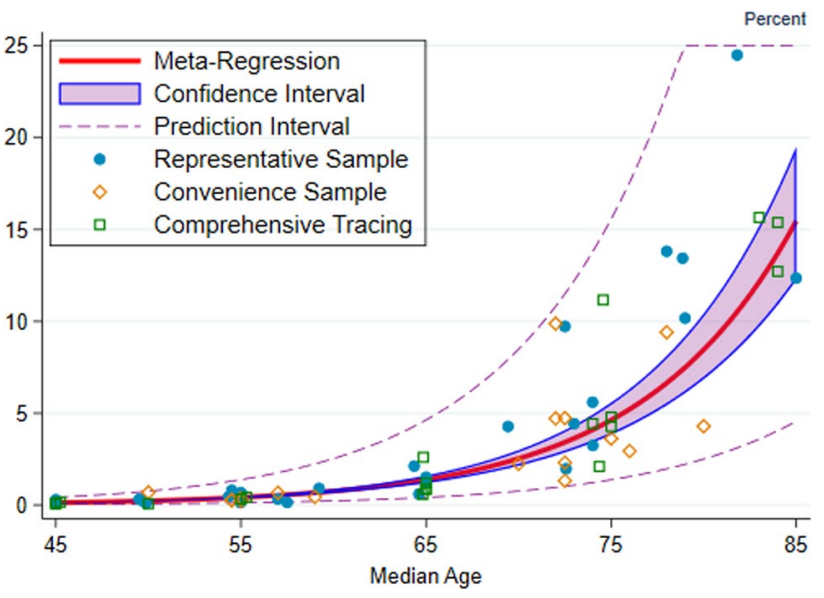

Fig. 4 Benchmark analysis of the link between age and IFR. Note: This figure depicts the relationship between the infection fatality rate (IFR) and age, where IFR is shown in percentage terms. Each marker denotes a specific metaregression observation, that is, the IFR for a particular age group in a particular location. The marker style reflects the type of observation: circles for observations from seroprevalence studies of representative samples, diamonds for seroprevalence studies of convenience samples, and squares for countries with comprehensive tracing programs. The red line denotes the metaregression estimate of IFR as a function of age, the shaded region depicts the 95\% confidence interval for that estimate. The dashed lines denote the prediction interval (which includes random variations across studies and age groups); almost all of the 104 metaregression observations lie within that interval

of excess mortality are broadly similar to our estimates [120, 145-147]. See Supplementary Appendix P for further discussion.

Our metaregression results are generally consistent with the study of Verity et al. [148] and Ferguson et al. [149], which were completed at an early stage of the COVID-19 pandemic and characterized an exponential pattern of agespecific IFRs (see Supplementary Appendix Q). Other subsequent studies have obtained broadly similar patterns of age-specific IFRs using statistical models to describe the dynamics of transmission and mortality using surveillance data in specific locations $[69,150]$.

Our findings are well-aligned with a recent meta-analysis of population IFR and indeed explain a high proportion of the dispersion in population IFRs highlighted by that study [151]. In contrast, our findings are markedly different from those of another review of population IFR that includes samples that did not satisfy our inclusion criteria [152].

The exponential pattern of our age-specific IFR estimates is qualitatively similar to that of case fatality rates (CFRs). However, the relative magnitudes are systematically different, reflecting the extent to which asymptomatic or mildly symptomatic cases are much more common in younger adults than in middle-aged and older adults. For example, the ratio of CFR to IFR is about 15:1 for ages 30-49, about 
Fig. 5 Forest plot of metaregression data

Cohorts with median age of 5-15 years

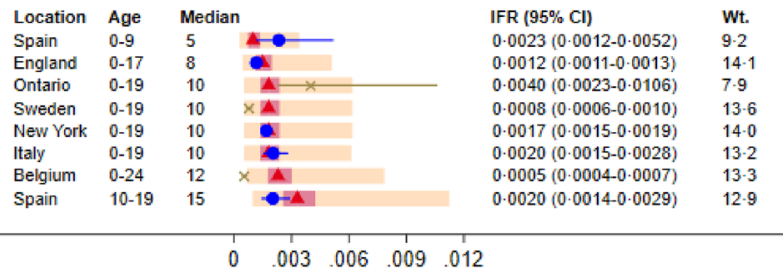

Cohorts with median age of $16-25$ years

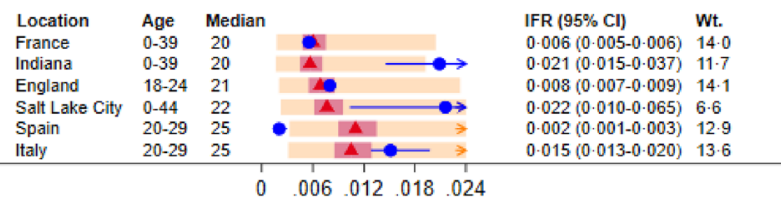

Cohorts with median age of 26-34 years

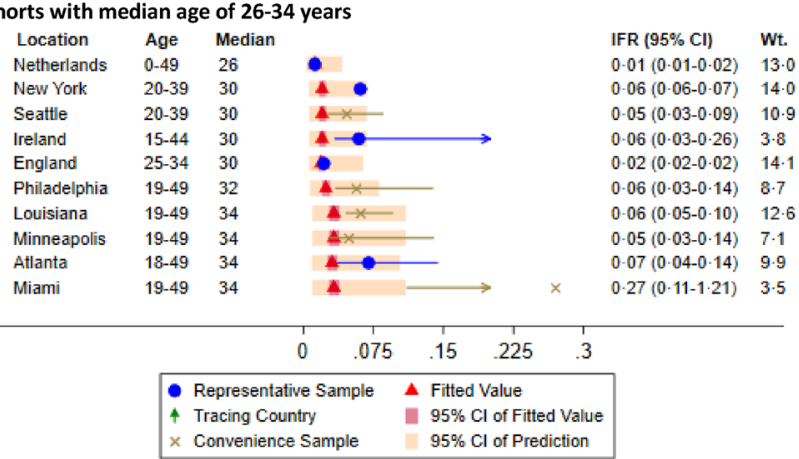

Cohorts with median age of 35-54 years

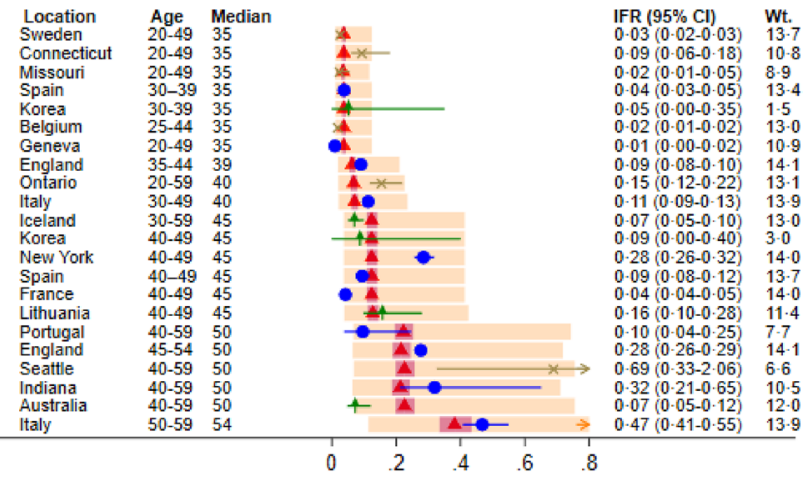

Cohorts with median age of 55-64 years

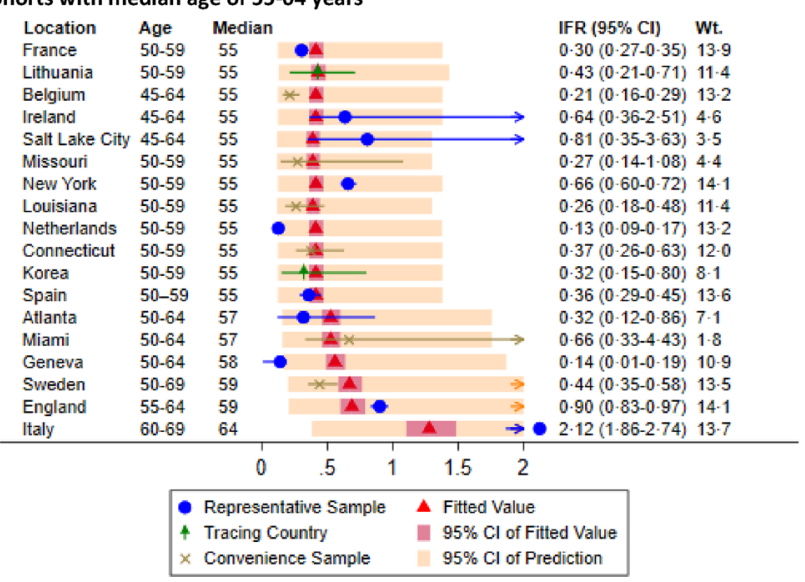


Fig. 5 (continued)

7:1 for ages 50-69, and about 5:1 for ages 70-79 years (see Supplementary Appendix R).

A potential concern about measuring IFR based on seroprevalence is that antibody titers may diminish over time, leading to underestimation of true prevalence and corresponding overestimation of IFR. This concern is particularly relevant for seroprevalence studies conducted many months after the outbreak was contained [153]. However, recent research has confirmed that production of spike-specific antibodies to SARS-CoV-2 persists in a very high proportion of individuals for at least 3 or 4 months, which is the relevant timeframe for nearly all of the seroprevalence studies used in our metaregression [91, 154]. Moreover, one recent study has demonstrated that incorporating seroreversion into measures of prevalence does not have a material impact on estimates of age-specific IFRs [155].

Moreover, a key feature of our metaregression analysis is that we also utilize age-specific IFR data based on RTPCR results (not seroprevalence) for five countries that have maintained comprehensive tracing programs since the onset of the pandemic, namely, Australia, Iceland, Korea, Lithuania, and New Zealand. As shown in Fig. 3, the age-specific IFRs for those five countries are well aligned with the metaregression predictions, indicating that these findings do not rely upon any specific method of gauging prevalence.
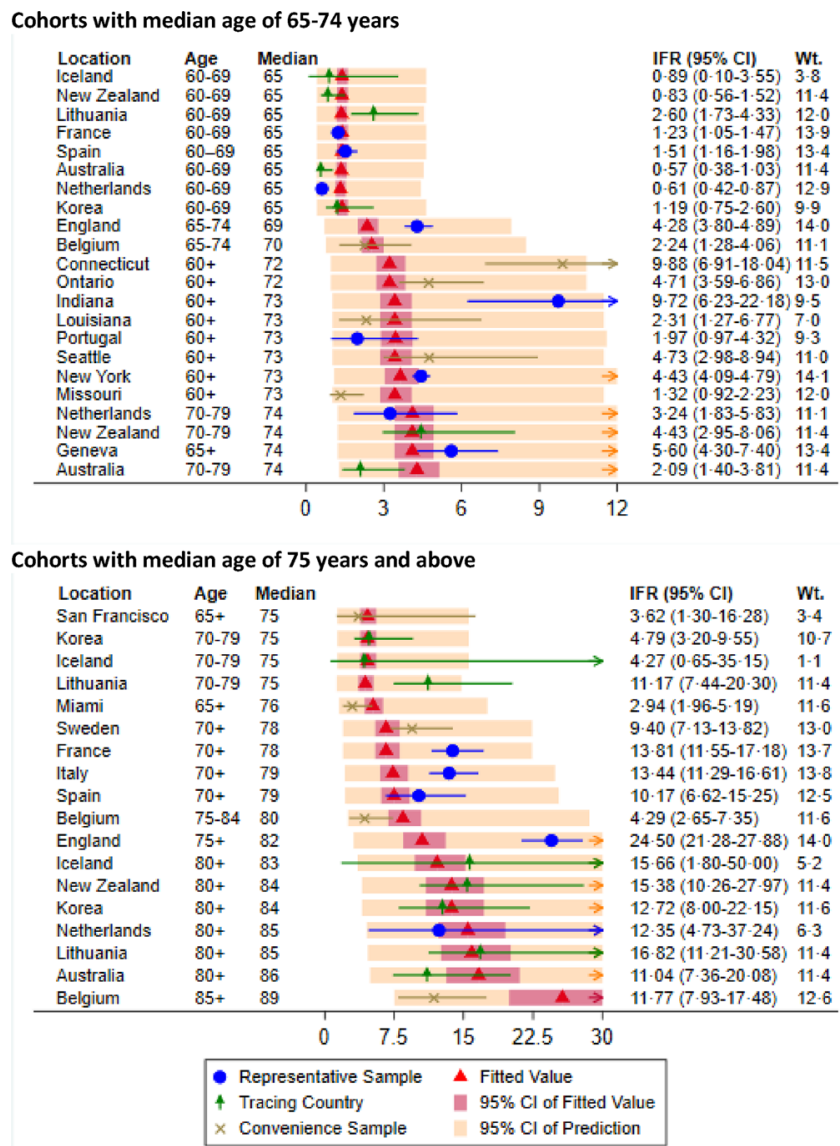

A substantial limitation of our work is that we have not considered factors apart from age that affect the IFR of COVID-19. For example, we have not considered the extent to which IFRs may vary with demographic factors such as race and ethnicity or potential causal interactions between these factors $[41,70]$. Likewise, our metaregression does not include measures of comorbidities such as diabetes or obesity [156]. However, a recent study of data from a large representative and longitudinal sample collected by U.K. Biobank found that measures of frailty and comorbidity had only moderate effects in predicting COVID-19 mortality risk (i.e., increased odds of about 10\%); moreover, that link was negligible among positive COVID-19 cases after accounting for age and sex [157]. See Supplementary Appendix S for additional evidence. Further research on these issues is clearly warranted.

Another limitation of our meta-analysis is that we have focused exclusively on assessing IFRs in advanced economies to facilitate comparability regarding health care provision and reporting of fatalities. Nonetheless, it is absolutely clear that the COVID-19 pandemic has had devastating consequences for lower-income and developing countries. For example, as of late October 2020, the reported COVID19 death counts were nearly 160 thousand in Brazil, 120 thousand in India, and 90 thousand in Mexico. And in many 


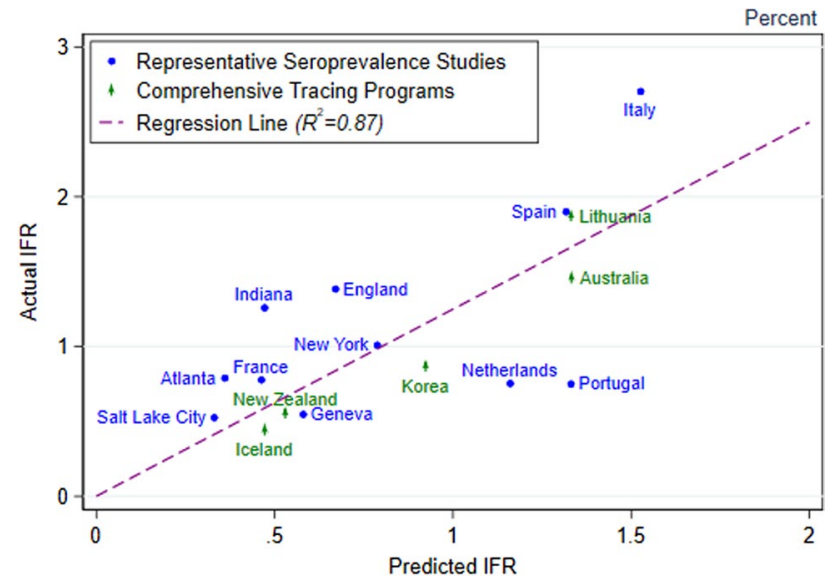

Fig. 6 Variations in population IFR across geographical locations. Note: This figure depicts the extent to which the metaregression results account for variations in population IFR across geographical locations. The blue circles denote seroprevalence studies of representative samples, and the green diamonds denote countries with comprehensive tracing programs. For each observation, its position on the horizontal axis denotes its predicted IFR obtained by aggregating across the age-specific predictions of the metaregression, and its position on the vertical axis denotes the actual population IFR for that location. The dashed segments denote the estimated line obtained by fitting a regression to these 16 observations. The $\mathrm{R}^{2}$ of this regression is 0.87 , indicating that nearly $90 \%$ of the variation in population IFR can be explained by variations in age composition and age-specific prevalence of COVID-19

Table 3 Age-specific fatality rates for COVID-19 infections vs. accidental deaths $(\%)$

\begin{tabular}{|c|c|c|c|c|c|}
\hline \multirow[t]{2}{*}{ Age group } & \multirow[t]{2}{*}{$\begin{array}{l}\text { COVID-19 IFR } \\
(95 \% \mathrm{CI})\end{array}$} & \multicolumn{2}{|c|}{$\begin{array}{l}\text { Automobile } \\
\text { fatalities }\end{array}$} & \multicolumn{2}{|c|}{$\begin{array}{l}\text { Other acciden- } \\
\text { tal fatalities }\end{array}$} \\
\hline & & England & USA & England & USA \\
\hline-34 & $0.004(0.003-0.005)$ & 0.002 & 0.015 & 0.004 & 0.032 \\
\hline $35-44$ & $0.068(0.058-0.078)$ & 0.002 & 0.012 & 0.017 & 0.043 \\
\hline $45-54$ & $0.23(0.20-0.26)$ & 0.002 & $0 . .013$ & 0.019 & 0.043 \\
\hline $55-64$ & $0.75(0.66-0.87)$ & 0.003 & 0.013 & 0.014 & 0.043 \\
\hline $65-74$ & $2.5(2.1-3.0)$ & 0.003 & 0.013 & 0.020 & 0.040 \\
\hline $75-84$ & $8.5(6.9-10.4)$ & 0.005 & 0.017 & 0.069 & 0.09 \\
\hline $85+$ & $28.3(21.8-36.6)$ & 0.007 & 0.019 & 0.329 & 0.349 \\
\hline
\end{tabular}

This table compares IFRs for COVID-19 with the incidence of accidental deaths in England and in the USA. For each age group, the second column shows the metaregression estimate of the age-specific IFR with its $95 \%$ confidence interval enclosed in parentheses. The final four columns report the annual incidence of automobile fatalities and other accidental fatalities as a percent of the population of each age group in each country. The accidental fatality data for England as of 2019 is reported by the U.K. Office of National Statistics, while the corresponding U.S. data are reported as of 2018 by the U.S. National Center for Health Statistics [142, 143] countries, measures of excess mortality are much higher than official tabulations of COVID-19 fatalities.

Consequently, analysis of prevalence and IFR is urgently needed to provide guidance to public health officials in developing countries [155, 158, 159]. However, the core findings of our meta-analysis may well be relevant even in those contexts. For example, recent prevalence studies of Manaus, Brazil found that about $66 \%$ of the population was infected with the SARS-CoV-2 virus between March and August 2020 [160, 161]. As of October, Manaus (a city with 1.8 million inhabitants) had 2853 confirmed COVID-19 deaths [162]. That outcome is remarkably consistent with our analysis, because nearly $90 \%$ of Manaus residents are under 50 years of age. Indeed, using the age structure of the Manaus population and assuming uniform prevalence of infections across age groups, our metaregression predicts a population IFR of $0.22 \%$ that is practically indistinguishable from the observed outcome of $0.2 \%$. (See Supplementary Appendix T.) Thus, our analysis provides a coherent explanation why Manaus was much less severely impacted by the pandemic compared to other locations with larger numbers of middle-aged and older adults.

Finally, it should be noted that our analysis has focused on assessing fatality risks but has not captured the full spectrum of adverse health consequences of COVID-19, some of which may be very severe and persistent. Further research is needed to assess age-stratified rates of hospitalization as well as longer-term sequelae attributable to SARS-CoV-2 infections. These factors are likely to be particularly important in quantifying overall risks to health care.

In summary, our analysis demonstrates that COVID-19 is not only dangerous for the elderly and infirm but also for healthy middle-aged adults. The metaregression explains nearly $90 \%$ of the geographical variation in population IFR, indicating that the population IFR is intrinsically linked to the age-specific pattern of infections. Consequently, public health measures to protect vulnerable age groups could substantially reduce the incidence of mortality.

Funding No funding was received for conducting this study. This study was preprinted at: https://www.medrxiv.org/conte nt/10.1101/2020.07.23.20160895v3.

\section{Compliance with ethical standards}

Conflict of interest The authors have no financial interests nor any other conflicts of interest related to this study.

Open Access This article is licensed under a Creative Commons Attribution 4.0 International License, which permits use, sharing, adaptation, distribution and reproduction in any medium or format, as long as you give appropriate credit to the original author(s) and the source, provide a link to the Creative Commons licence, and indicate if changes were made. The images or other third party material in this article are 
included in the article's Creative Commons licence, unless indicated otherwise in a credit line to the material. If material is not included in the article's Creative Commons licence and your intended use is not permitted by statutory regulation or exceeds the permitted use, you will need to obtain permission directly from the copyright holder. To view a copy of this licence, visit http://creativecommons.org/licenses/by/4.0/.

\section{References}

1. Khalili M, Karamouzian M, Nasiri N, Javadi S, Mirzazadeh A, Sharifi H. Epidemiological characteristics of COVID19: a systematic review and meta-analysis. Epidemiol Infect. 2020;148:e130. https://doi.org/10.1017/S0950268820001430.

2. Oran DP, Topol EJ. Prevalence of asymptomatic SARS-CoV-2 infection: a narrative review. Ann Intern Med. 2020. https://doi. org/10.7326/M20-3012.

3. Li R, Pei S, Chen B, et al. Substantial undocumented infection facilitates the rapid dissemination of novel coronavirus (SARSCoV-2). Science. 2020;368(6490):489. https://doi.org/10.1126/ science.abb3221.

4. Li H, Wang S, Zhong F, et al. Age-dependent risks of incidence and mortality of COVID-19 in Hubei Province and other parts of China. Front Med (Lausanne). 2020;7:190. https://doi. org/10.3389/fmed.2020.00190.

5. Dudel C, Riffe T, Acosta E, van Raalte A, Strozza C, Myrskylä M. Monitoring trends and differences in COVID-19 case-fatality rates using decomposition methods: Contributions of age structure and age-specific fatality. PLoS ONE. 2020;15(9):e0238904. https://doi.org/10.1371/journal.pone.0238904.

6. Moraga P, Ketcheson D, Ombao H, Duarte C. Assessing the ageand gender-dependence of the severity and case fatality rates of COVID-19 disease in Spain. 2020. https://doi.org/10.12688/ wellcomeopenres.15996.1

7. Byambasuren O, Dobler CC, Bell K, et al. Estimating The seroprevalence of SARS-CoV-2 infections: systematic review. 2020. medRxiv. https://doi.org/10.1101/2020.07.13.20153163

8. Arora RK, Joseph A, Van Wyk J, et al. SeroTracker: a global SARS-CoV-2 seroprevalence dashboard. Lancet Infect Dis. 2020. https://doi.org/10.1016/s1473-3099(20)30631-9.

9. Seoane B. A scaling approach to estimate the COVID19 infection fatality ratio from incomplete data. medRxiv. 2020:2020.06.05.20123646. doi:https://doi. org/10.1101/2020.06.05.20123646

10. Rosenberg ES, Tesoriero JM, Rosenthal EM, et al. Cumulative incidence and diagnosis of SARS-CoV-2 infection in New York. Ann Epidemiol. 2020. https://doi.org/10.1016/J.ANNEP IDEM.2020.06.004.

11. New York City Department of Health. COVID-19 Data. 2020.

12. Shook-Sa BE, Boyce RM, Aiello AE. Estimation without Representation: Early SARS-CoV-2 Seroprevalence Studies and the Path Forward. J Infect Dis. 2020. https://doi.org/10.1093/INFDI S/JIAA429.

13. Brown TS, Walensky RP. Serosurveillance and the COVID-19 epidemic in the US: undetected, uncertain, and out of control. JAMA. 2020. https://doi.org/10.1001/jama.2020.14017.

14. Flower B, Atchison C. SARS-CoV-2 antibody seroprevalence in patients receiving dialysis in the USA. Lancet. 2020. https://doi. org/10.1016/S0140-6736(20)32006-7.

15. Meyerowitz-Katz G, Merone L. A systematic review and metaanalysis of published research data on COVID-19 infection fatality rates. Int J Infect Dis. 2020;101:138-48. https://doi. org/10.1016/j.jiid.2020.09.1464.
16. United Kingdom Parliament Office. Antibody tests for COVID19. 2020.

17. Organization for Economic Cooperation and Development. Member countries. 2020.

18. Lattimore S, Wickenden C, Brailsford SR. Blood donors in England and North Wales: demography and patterns of donation. Transfusion. 2015;55(1):91-9. https://doi.org/10.1111/trf.12835.

19. Public Health England. Sero-surveillance of COVID-19: week 22. 2020.

20. United Kingdom Office for National Statistics. Coronavirus (COVID-19) infection survey: characteristics of people testing positive for COVID-19 in England, August 2020. 2020.

21. Clarke C, Prendecki M, Dhutia A, et al. High prevalence of asymptomatic COVID-19 infection in hemodialysis patients detected using serologic screening. J Am Soc Nephrol. 2020. https://doi.org/10.1681/ASN.2020060827.

22. Ward H, Atchison CJ, Whitaker M, et al. Antibody prevalence for SARS-CoV-2 in England following first peak of the pandemic: REACT2 study in 100,000 adults. medRxiv. 2020:2020.08.12.20173690. doi:https://doi. org/10.1101/2020.08.12.20173690

23. Anand S, Montez-Rath M, Han J, et al. Prevalence of SARSCoV-2 antibodies in a large nationwide sample of patients on dialysis in the USA: a cross-sectional study. Lancet. 2020. https ://doi.org/10.1016/S0140-6736(20)32009-2.

24. Japan Ministry of Health Labour and Welfare. Updates on COVID-19 in Japan. 2020.

25. Takita M, Matsumura T, Yamamoto K, et al. Geographical profiles of COVID-19 outbreak in Tokyo: an analysis of the primary care clinic-based point-of-care antibody testing. J Prim Care Community Health. 2020;11:2150132720942695. https://doi. org/10.1177/2150132720942695.

26. Snoeck CJ, Vaillant M, Abdelrahman T, et al. Prevalence of SARS-CoV-2 infection in the Luxembourgish population: the CON-VINCE study. 2020. medRxiv. https://doi. org/10.1101/2020.05.11.20092916

27. Havers FP, Reed C, Lim T, et al. Seroprevalence of antibodies to SARS-CoV-2 in 10 sites in the United States, March 23-May 12, 2020. JAMA Intern Med. 2020. https://doi.org/10.1001/jamai nternmed.2020.4130.

28. University of Utah Health. Utah HERO project announces phase one findings. 2020.

29. Our World in Data. Coronavirus (COVID-19) testing: tests per confirmed case. 2020. https://ourworldindata.org/coronaviru s-testing\#tests-per-confirmed-case. Accessed 18 Aug.

30. Gudbjartsson DF, Helgason A, Jonsson H, et al. Spread of SARS-CoV-2 in the Icelandic population. N Engl J Med. 2020;382(24):2302-15. https://doi.org/10.1056/NEJMoa2006 100.

31. Korea Center for Disease Control. Updates on COVID-19 in Korea as of July 9. 2020.

32. Song SK, Lee DH, Nam JH, et al. IgG Seroprevalence of COVID-19 among Individuals without a History of the Coronavirus Disease Infection in Daegu. Korea Journal of Korean medical science. 2020;35(29):e269-e. https://doi.org/10.3346/ jkms.2020.35.e269.

33. Byrne AW, McEvoy D, Collins AB, et al. Inferred duration of infectious period of SARS-CoV-2: rapid scoping review and analysis of available evidence for asymptomatic and symptomatic COVID-19 cases. BMJ Open. 2020;10(8):e039856-e. https://doi. org/10.1136/bmjopen-2020-039856.

34. Long QX, Liu BZ, Deng HJ, et al. Antibody responses to SARSCoV-2 in patients with COVID-19. Nat Med. 2020;26(6):845-8. https://doi.org/10.1038/s41591-020-0897-1. 
35. Sethuraman N, Jeremiah SS, Ryo A. Interpreting diagnostic tests for SARS-CoV-2. JAMA. 2020;323(22):2249-51. https://doi. org/10.1001/jama.2020.8259.

36. Choe PG, Kang CK, Suh HJ, et al. Antibody responses to SARS$\mathrm{CoV}-2$ at 8 weeks postinfection in asymptomatic patients. Emerg Infect Dis J. 2020. https://doi.org/10.3201/eid2610.202211.

37. Ripperger TJ, Uhrlaub JL, Watanabe M, et al. Detection, prevalence, and duration of humoral responses to SARS$\mathrm{CoV}-2$ under conditions of limited population exposure. medRxiv. 2020:2020.08.14.20174490. doi:https://doi. org/10.1101/2020.08.14.20174490

38. U.S. Center for Disease Control and Prevention. COVID-19 pandemic planning scenarios. 2020.

39. Harbord RM, Higgins JPT. Meta-regression in Stata. Stata J. 2008;8(4):493-519.

40. Higgins JPT, Thompson SG, Spiegelhalter DJ. A re-evaluation of random-effects meta-analysis. J R Stat Soc Ser A Stat Soc. 2009;172(1):137-59. https://doi.org/10.1111/j.1467985X.2008.00552.x.

41. Chamie G, Marquez C, Crawford E, et al. SARS-CoV-2 community transmission disproportionately affects Latinx population during shelter-in-place in San Francisco. Clin Infect Dis. 2020. https://doi.org/10.1093/cid/ciaa1234

42. Czech Ministry of Health. Collective immunity study SARSCoV-2: Czech prevalence. 2020.

43. Denmark State Blood Institute. Notat: Nye foreløbige resultater fra den repræsentative seroprævalensunders $\varnothing$ gelse af COVID19. 2020.

44. Dimeglio C, Loubes J-M, Miedougé M, Herin F, Soulat J-M, Izopet J. The real seroprevalence of SARS-CoV-2 in France and its consequences for virus dynamics. 2020. J Infect. 81:318-356. https://doi.org/10.1016/j.jinf.2020.04.031

45. Jersey Health \& Community Services. Prevalence of antibodies: community survey round 2. 2020.

46. Lavezzo E, Franchin E, Ciavarella C, et al. Suppression of COVID-19 outbreak in the municipality of Vo, Italy. Nature. 2020;584:425-9. https://doi.org/10.1038/s41586-020-2488-1.

47. Mahajan S, Srinivasan R, Redlich CA, et al. Seroprevalence of SARS-CoV-2-specific IgG antibodies among adults living in connecticut between March 1 and June 1, 2020: post-infection prevalence (PIP) study. medRxiv. 2020:2020.08.04.20168203. https://doi.org/10.1101/2020.08.04.20168203

48. McLaughlin CC, Doll MK, Morrison KT, et al. High community SARS-CoV-2 antibody seroprevalence in a ski resort community, Blaine County, Idaho, US. Preliminary results. medRxiv. 2020. doi:https://doi.org/10.1101/2020.07.19.20157 198

49. Nawa N, Kuramochi J, Sonoda S, et al. Seroprevalence of SARS-CoV-2 IgG Antibodies in Utsunomiya City, Greater Tokyo, after first pandemic in 2020 (U-CORONA): a household- and population-based study. medRxiv. 2020. https://doi. org/10.1101/2020.07.20.20155945

50. Nishiura H, Kobayashi T, Yang Y, et al. The rate of underascertainment of novel coronavirus (2019-nCoV) infection: estimation using Japanese passengers data on evacuation flights. J Clin Med. 2020. https://doi.org/10.3390/jcm9020419.

51. Norrbotten Region. Forekomst av antikroppar mot covid-19Norrbottens befolkning maj 2020. 2020.

52. Norway Public Health Institute. Truleg berre ein liten andel av befolkninga som har vore smitta av koronavirus. 2020.

53. Oklahoma State Department of Health. Weekly epidemiology and surveillance report. 2020.

54. Oregon State University. TRACE results suggest $17 \%$ of Hermiston community infected with SARS-CoV-2. 2020.
55. Petersen MS, Strøm M, Christiansen DH, et al. Seroprevalence of SARS-CoV-2-specific antibodies, Faroe Islands. Emerg Infect Dis. 2020. https://doi.org/10.3201/EID2611.202736.

56. Rhode Island Department of Health. COVID-19 serology testing brief. 2020.

57. Riverside County Joint Information Center. Antibody study shows coronavirus spread wider in Riverside County. 2020.

58. Naranbhai V, Chang C, Beltran W, et al. High seroprevalence of anti-SARS-CoV-2 antibodies in Chelsea, Massachusetts. J Infect Dis. 2020;222:1955-9. https://doi.org/10.1093/infdis/jiaa579.

59. San Miguel County Department of Health \& Environment. IgG antibody tests: statistics and demographics. 2020.

60. Skowronski DM, Sekirov I, Sabaiduc S, et al. Low SARS-CoV-2 sero-prevalence based on anonymized residual sero-survey before and after first wave measures in British Columbia. Canada: March-May; 2020. p. 2020.

61. Slovenia Government Communication Office. First study carried out on herd immunity of the population in the whole territory of Slovenia. 2020.

62. Stadlbauer D, Tan J, Jiang K, et al. Seroconversion of a city: longitudinal monitoring of SARS-CoV-2 seroprevalence in New York City. medRxiv. 2020:2020.06.28.20142190. https://doi. org/10.1101/2020.06.28.20142190

63. Stockholm Region. Lägesrapport om arbetet med det nya coronaviruset. 2020.

64. Streeck H, Schulte B, Kuemmerer B, et al. Infection fatality rate of SARS-CoV-2 infection in a German community with a super-spreading event. 2020. Nat Commun 11:5829. https://doi. org/10.1038/s41467-020-19509-y.

65. University of Miami. SPARK-C: understanding the burden of COVID-19 in Miami-Dade County through rapid serological testing of a representative random sample. 2020.

66. Washoe County Health District. Seroprevalence of SARS-CoV-2 specific antibodies among adults in Washoe County, Nevada on June 9-10, 2020. 2020.

67. Weis S, Scherag A, Baier M, et al. Seroprevalence of SARSCoV-2 antibodies in an entirely PCR-sampled and quarantined community after a COVID-19 outbreak: the CoNAN study. medRxiv. 2020. https://doi.org/10.1101/2020.07.15.20154 112

68. Wells PM, Doores KM, Couvreur S, et al. Estimates of the rate of infection and asymptomatic COVID-19 disease in a population sample from SE England. 2020.

69. Sweden Public Health Authority. the infection fatality rate of COVID-19 in Stockholm: technical report. 2020.

70. Feehan AK, Fort D, Garcia-Diaz J, et al. Seroprevalence of SARS-CoV-2 and infection fatality ratio, Orleans and Jefferson Parishes, Louisiana, USA, May 2020. Emerg Infect Dis. 2020. https://doi.org/10.3201/eid2611.203029.

71. Giustizia News. Coronavirus, l'incubo senza fine di Ariano Irpino: 60 positivi al tampone dopo i test sierologici. May 28.

72. Austria Statistik. COVID-19 prevalence study: a maximum of $0.15 \%$ of the population in Austria infected with SARS-CoV-2. 2020.

73. Saltzman J. Study: 1 out of 10 residents in 4 neighborhoods unwittingly had coronavirus. Boston Globe. 2020 May 15.

74. Micolitti A. Caldari Ortona: $12 \%$ cittadini sottoposti a test sierologici positivi con anticorpi al Covid 19. Rete8. 2020 June 3.

75. Finland National Institute for Health and Welfare. Weekly report of THL serological population study of the coronavirus epidemic. 2020.

76. Bogogiannidou Z, Vontas A, Dadouli K, et al. Repeated leftover serosurvey of SARS-CoV-2 IgG antibodies, Greece, March and April 2020. Eurosurveillance. 2020;25(31):2001369. https://doi. org/10.2807/1560-7917.ES.2020.25.31.2001369. 
77. Times of Israel Staff. Coronavirus : Israël est encore loin de l'immunité de groupe. Times of Israel. 2020 July 23.

78. Aziz NA, Corman VM, Echterhoff AKC, et al. Seroprevalence and correlates of SARS-CoV-2 neutralizing antibodies: results from a population-based study in Bonn, Germany. medRxiv. 2020:2020.08.24.20181206. doi:https://doi. org/10.1101/2020.08.24.20181206

79. CBC News. Serology study gives officials first look at spread of COVID-19 through Alberta's population. 2020 July 30.

80. Feehan AK, Velasco C, Fort D, et al. Racial and workplace disparities in seroprevalence of SARS-CoV-2 in Baton Rouge, Louisiana, July 15-31, 2020. medRxiv. 2020:2020.08.26.20180968. doi:https://doi.org/10.1101/2020.08.26.20180968

81. Hicks S, Pohl K, Neeman T, et al. A dual antigen ELISA allows the assessment of SARS-CoV-2 antibody seroprevalence in a low transmission setting. medRxiv. 2020:2020.09.09.20191031. doi:https://doi.org/10.1101/2020.09.09.20191031

82. Lundkvist $\AA$, Hanson S, Olsen B. Pronounced difference in Covid-19 antibody prevalence indicates cluster transmission in Stockholm, Sweden. Infect Ecol Epidemiol. 2020;10(1):1806505. https://doi.org/10.1080/20008686.2020.1806505.

83. University of Louisville School of Medicine. Phase II results of Co-Immunity Project show higher-than-expected rates of exposure to novel coronavirus in Jefferson County. 2020.

84. van den Broek-Altenburg E, Atherly A, Diehl S, et al. Risk factors for COVID-19: community exposure and mask-wearing. 2020. doi:https://doi.org/10.2139/ssrn.3676570

85. Knabl L, Mitra T, Kimpel J, et al. High SARS-CoV-2 Seroprevalence in children and adults in the Austrian ski resort Ischgl. medRxiv. 2020:2020.08.20.20178533. doi:https://doi. org/10.1101/2020.08.20.20178533

86. Naranbhai V, Chang CC, Beltran WFG, et al. High seroprevalence of anti-SARS-CoV-2 antibodies in Chelsea, Massachusetts. J Infect Dis. 2020. https://doi.org/10.1093/infdis/jiaa579.

87. Fenwick C, Croxatto A, Coste AT, et al. Changes in SARS-CoV-2 antibody responses impact the estimates of infections in population-based seroprevalence studies. medRxiv. 2020:2020.07.14.20153536. doi:https://doi. org/10.1101/2020.07.14.20153536

88. Figueiredo-Campos P, Blankenhaus B, Mota C, et al. Seroprevalence of anti-SARS-CoV-2 antibodies in COVID-19 patients and healthy volunteers. medRxiv. 2020:2020.08.30.20184309. doi:https://doi.org/10.1101/2020.08.30.20184309

89. Hibino S, Hayashida K, Ahn AC, Hayashida Y. Dynamic change of COVID-19 seroprevalence among asymptomatic population in Tokyo during the second wave. medRxiv. 2020:2020.09.21.20198796. doi:https://doi. org/10.1101/2020.09.21.20198796

90. Northeast Texas Public Health Department. Hideaway COVID19 antibody testing program. 2020.

91. Ripperger TJ, Uhrlaub JL, Watanabe M, et al. Orthogonal SARSCoV-2 Serological Assays Enable Surveillance of Low Prevalence Communities and Reveal Durable Humoral Immunity. Immunity. 2020. https://doi.org/10.1016/j.immuni.2020.10.004.

92. Reifer J, Hayum N, Heszkel B, Klagsbald I, Streva VA. SARSCoV-2 IgG antibody responses in New York City. Diagn Microbiol Infect Dis. 2020. https://doi.org/10.1016/J.DIAGMICROB IO.2020.11512.

93. Merkely B, Szabo AJ, Kosztin A, et al. Novel coronavirus epidemic in the Hungarian population, a cross-sectional nationwide survey to support the exit policy in Hungary. Geroscience. 2020;42(4):1063-74. https://doi.org/10.1007/s11357-020-00226 -9 .

94. Sutton M, Cieslak P, Linder M. Seroprevalence estimates of SARS-CoV-2 infection in convenience sample-Oregon, May
11-June 15. Morb Mortal Wkly Report. 2020;69:1100-1. https ://doi.org/10.15585/mmwr.mm6932a4.

95. Armann JP, Unrath M, Kirsten C, Lueck C, Dalpke A, Berner R. Anti-SARS-CoV-2 IgG antibodies in adolescent students and their teachers in Saxony, Germany (SchoolCoviDD19): very low seropraevalence and transmission rates. 2020. doi:https:// doi.org/10.1101/2020.07.16.20155143

96. Bendavid E, Mulaney B, Sood N, et al. COVID-19 antibody seroprevalence in Santa Clara County, California. medRxiv. 2020. https://doi.org/10.1101/2020.04.14.20062463

97. Bryan A, Pepper G, Wener MH, et al. Performance characteristics of the Abbott Architect SARS-CoV-2 IgG assay and seroprevalence in Boise, Idaho. J Clin Microbiol. 2020. https://doi. org/10.1128/JCM.00941-20.

98. Erikstrup C, Hother CE, Pedersen OBV, et al. Estimation of SARS-CoV-2 infection fatality rate by real-time antibody screening of blood donors. Clin Infect Dis. 2020. https://doi. org/10.1093/CID/CIAA849.

99. Fiore J, Centra M, de Carlo A, et al. Far away from herd immunity to SARS-CoV-2: results from a survey in healthy blood donors in southeastern Italy. 2020. doi:https://doi. org/10.1101/2020.06.17.20133678

100. Fischer B, Knabbe C, Vollmer T. SARS-CoV-2 IgG seroprevalence in blood donors located in three different federal states, Germany, March to June 2020. Euro Surveill. 2020. https://doi. org/10.2807/1560-7917.ES.2020.25.28.2001285.

101. Fontanet A, Tondeur L, Madec Y, et al. Cluster of COVID19 in northern France: a retrospective closed cohort study. medRxiv. 2020:2020.04.18.20071134. doi:https://doi. org/10.1101/2020.04.18.20071134

102. Kraehling V, Kern M, Halwe S, et al. Epidemiological study to detect active SARS-CoV-2 infections and seropositive persons in a selected cohort of employees in the Frankfurt am Main metropolitan area. medRxiv. 2020. https://doi. org/10.1101/2020.05.20.20107730

103. Nesbitt DJ, Jin D, Hogan JW, et al. Low seroprevalence of SARS-CoV-2 in Rhode Island blood donors determined using multiple serological assay formats. medRxiv. 2020. https://doi. org/10.1101/2020.07.20.20157743

104. Ng D, Goldgof G, Shy B, et al. SARS-CoV-2 seroprevalence and neutralizing activity in donor and patient blood from the San Francisco Bay Area. medRxiv. 2020. doi:https://doi. org/10.1101/2020.05.19.20107482

105. Percivalle E, Cambie G, Cassaniti I, et al. Prevalence of SARS-CoV-2 specific neutralising antibodies in blood donors from the Lodi Red Zone in Lombardy, Italy, as at 06 April 2020. Euro Surveill. 2020. https://doi.org/10.2807/1560-7917. ES.2020.25.24.2001031.

106. Slot E, Hogema BM, Reusken CBEM, et al. Herd immunity is not a realistic exit strategy during a COVID-19 outbreak. 2020. doi:https://doi.org/10.21203/rs.3.rs-25862/v1

107. Thompson CP, Grayson N, Paton R, et al. Detection of neutralising antibodies to SARS coronavirus 2 to determine population exposure in Scottish blood donors between March and May 2020. medRxiv. 2020:2020.04.13.20060467. doi:https://doi. org/10.1101/2020.04.13.20060467

108. Valenti L, Bergna A, Pelusi S, et al. SARS-CoV-2 seroprevalence trends in healthy blood donors during the COVID-19 Milan outbreak. medRxiv. 2020. https://doi.org/10.1101/2020.05.11.20098 442

109. Doi A, Iwata K, Kuroda H, et al. Estimation of seroprevalence of novel coronavirus disease (COVID-19) using preserved serum at an outpatient setting in Kobe, Japan: a cross-sectional study. medRxiv. 2020. https://doi.org/10.1101/2020.04.26.20079822 
110. Emmenegger M, Cecco ED, Lamparter D, et al. Population-wide evolution of SARS-CoV-2 immunity tracked by a ternary immunoassay. medRxiv. 2020. https://doi. org/10.1101/2020.05.31.20118554

111. Canadian Blood Services. COVID-19 seroprevalence reportAugust 19, 2020. 2020.

112. Poletti P, Tirani M, Cereda D, et al. Age-specific SARS-CoV-2 infection fatality ratio and associated risk factors, Italy, February to April 2020. Euro surveillance : bulletin Europeen sur les maladies transmissibles $=$ European communicable disease bulletin. 2020;25(31):2001383. doi:https://doi.org/10.2807/1560-7917. ES.2020.25.31.2001383

113. Rigatti SJ, Stout R. SARS-CoV-2 antibody prevalence and association with routine laboratory values in a life insurance applicant population. medRxiv. 2020:2020.09.09.20191296. doi:https:// doi.org/10.1101/2020.09.09.20191296

114. Toenshoff B, Muller B, Elling R, et al. Prevalence of SARSCoV-2 infection in children and their parents in Southwest Germany. 2020. doi:https://doi.org/10.2139/ssrn.3668418

115. Dodd RY, Xu M, Stramer SL. Change in donor characteristics and antibodies to SARS-CoV-2 in donated blood in the US, June-August 2020. JAMA. 2020. https://doi.org/10.1001/ jama.2020.18598.

116. Ulyte A, Radtke T, Abela IA, et al. Variation in SARS-CoV-2 seroprevalence in school-children across districts, schools and classes. medRxiv. 2020:2020.09.18.20191254. doi:https://doi. org/10.1101/2020.09.18.20191254

117. Vassallo RR, Bravo MD, Dumont LJ, Hazegh K, Kamel H. Seroprevalence of antibodies to SARS-CoV-2 in US blood donors. medRxiv. 2020:2020.09.17.20195131. doi:https://doi. org/10.1101/2020.09.17.20195131

118. Biggs HM. Estimated community seroprevalence of SARSCoV-2 antibodies-two Georgia Counties, April 28-May 3, 2020. Morb Mortal Wkly Rep 2020;69(29):965-70. doi:https:// doi.org/10.15585/MMWR.MM6929E2

119. Italy National Institute of Statistics. Primi risultati dell'indagine di sieroprevalenza sul SARS-CoV-2. 2020.

120. Pastor-Barriuso R, Perez-Gomez B, Hernan MA, et al. SARS$\mathrm{CoV}-2$ infection fatality risk in a nationwide seroepidemiological study. medRxiv. 2020:2020.08.06.20169722. doi:https://doi. org/10.1101/2020.08.06.20169722

121. Perez-Saez J, Lauer SA, Kaiser L, et al. Serology-informed estimates of SARS-CoV-2 infection fatality risk in Geneva, Switzerland. Lancet Infect Dis. 2020. https://doi.org/10.1016/S1473 -3099(20)30584-3.

122. Netherlands National Institute for Public Health and the Environment. Children and COVID-19. 2020.

123. Portugal National Institute of Health. Relatório de Apresentação dos Resultados Preliminares do Primeiro Inquérito Serológico Nacional COVID-19. 2020.

124. Menachemi N, Yiannoutsos CT, Dixon BE, et al. Population point prevalence of SARS-CoV-2 infection based on a statewide random sample-Indiana, April 25-29, 2020. Morb Mortal Wkly Rep. 2020;69(29):960-4. https://doi.org/10.15585/MMWR. MM6929E1.

125. Ireland Health Service Executive. Preliminary report of the results of the study to investigate COVID-19 infection in people living in Ireland (SCOPI): a national seroprevalence study, JuneJuly 2020. 2020.

126. Waterfield T, Watson C, Moore R, et al. Seroprevalence of SARS-CoV-2 antibodies in children: a prospective multicentre cohort study. medRxiv. 2020:2020.08.31.20183095. doi:https:// doi.org/10.1101/2020.08.31.20183095

127. Carrat F, de Lamballerie $X$, Rahib D, et al. Seroprevalence of SARS-CoV-2 among adults in three regions of France following the lockdown and associated risk factors: a multicohort study. medRxiv. 2020:2020.09.16.20195693. doi:https://doi. org/10.1101/2020.09.16.20195693

128. Molenberghs G, Faes C, Aerts J, et al. Belgian Covid-19 mortality, excess deaths, number of deaths per million, and infection fatality rates (8 March-9 May 2020). medRxiv. 2020. https://doi. org/10.1101/2020.06.20.20136234

129. Sweden Public Health Authority. Seroprevalence of antibodies following COVID-19 infection in blood samples from outpatient care, interim report 1, updated on June 18 using data thru week 21-Påvisning av antikroppar efter genomgången covid-19 i blodprov från öppenvården, delrapport 1 - uppdaterad 2020-0618 med data för prover insamlade vecka 21. 2020.

130. Ontario Public Health. COVID-19 seroprevalence in Ontario: March 27, 2020 to June 30, 2020. 2020.

131. Australia Department of Health. Coronavirus (COVID-19) current situation and case numbers. 2020.

132. Iceland Directorate of Health. COVID-19 in Iceland-statistics $28 \mathrm{Feb}$ to 14 June 2020. 2020.

133. Korea Center for Disease Control. Weekly report on the COVID19 situation in the Republic of Korea. 2020.

134. Lithuania Central Registry. Koronaviruso (COVID-19) Lietuvoje statistika. 2020.

135. New Zealand Ministry of Health. COVID-19 current cases. 2020.

136. United Kingdom BioBank. UK Biobank SARS-CoV-2 serology study weekly report-21 July 2020. 2020.

137. Mizumoto K, Kagaya K, Zarebski A, Chowell G. Estimating the asymptomatic proportion of coronavirus disease 2019 (COVID-19) cases on board the Diamond Princess cruise ship, Yokohama, Japan, 2020. Eurosurveillance. 2020. https://doi. org/10.2807/1560-7917.ES.2020.25.10.2000180.

138. Pagani G, Conti F, Giacomelli A, et al. Seroprevalence of SARS-CoV-2 significantly varies with age: preliminary results from a mass population screening. J Infect. 2020. https://doi. org/10.1016/j.jinf.2020.09.021.

139. France Public Health. COVID-19: point épidémiologique du 9 juillet 2020. 2020.

140. Davies NG, Klepac P, Liu Y, et al. Age-dependent effects in the transmission and control of COVID-19 epidemics. Nat Med. 2020. https://doi.org/10.1038/s41591-020-0962-9.

141. Acemoglu D, Chernozhukov V, Werning I, Whinston M. Optimal targeted lockdowns in a multi-group SIR model. National Bureau of Economic Research Working Paper 27102. 2020.

142. U.S. National Center for Health Statistics. Underlying cause of death, 1999-2018. 2020.

143. United Kingdom Office of National Statistics. Mortality statistics-underlying cause, sex and age. 2020.

144. World Health Organization. Coronavirus disease (COVID-19): similarities and differences with influenza. 2020.

145. Blackburn J, Yiannoutsos CT, Carroll AE, Halverson PK, Menachemi N. Infection fatality ratios for COVID-19 among noninstitutionalized persons 12 and older: results of a randomsample prevalence study. Ann Intern Med. 2020. https://doi. org/10.7326/M20-5352.

146. O'Driscoll M, Ribeiro Dos Santos G, Wang L, et al. Age-specific mortality and immunity patterns of SARS-CoV-2 infection in 45 countries. medRxiv. 2020:2020.08.24.20180851. doi:https://doi.org/10.1101/2020.08.24.20180851

147. Martin-Olalla JM. Age and sex disaggregation of crude excess deaths during the 2020 spring COVID-19 outbreak in Spain. medRxiv. 2020:2020.08.06.20169326. doi:https://doi. org/10.1101/2020.08.06.20169326

148. Verity R, Okell LC, Dorigatti I, et al. Estimates of the severity of coronavirus disease 2019: a model-based analysis. Lancet Infect Dis. 2020;20(6):669-77. https://doi.org/10.1016/S1473 $-3099(20) 30243-7$. 
149. Ferguson N, Laydon D, Nedjati-Gilani G, et al. Report 9: Impact of non-pharmaceutical interventions (NPIs) to reduce COVID-19 mortality and healthcare demand. 2020.

150. Hauser A, Counotte MJ, Margossian CC, et al. Estimation of SARS-CoV-2 mortality during the early stages of an epidemic: a modeling study in Hubei, China, and six regions in Europe. PLOS Medicine. 2020;17(7):e1003189. https://doi. org/10.1371/journal.pmed.1003189.

151. Meyerowitz-Katz G, Merone L. A systematic review and metaanalysis of published research data on COVID-19 infectionfatality rates. 2020 .

152. Ioannidis J. Infection fatality rate of COVID-19 inferred from seroprevalence data. Bull World Health Organ. 2020. https:// www.who.int/bulletin/online_first/BLT.20.265892.pdf

153. Ward H, Cooke G, Atchison C. Declining prevalence of antibody positivity to SARS-CoV-2: a community study of 365,000 adults. 2020

154. Gudbjartsson DF, Norddahl GL, Melsted P, et al. Humoral immune response to SARS-CoV-2 in Iceland. N Engl J Med. 2020. https://doi.org/10.1056/NEJMoa2026116.

155. Brazeau N, Verity R, Jenks S, et al. COVID-19 infection fatality ratio: estimates from seroprevalence. 2020. doi:https://doi. org/10.25561/83545.

156. Kang S-J, Jung SI. Age-related morbidity and mortality among patients with COVID-19. Infect Chemother. 2020;52(2):154-64.

157. Mak JKL, Kuja-Halkola R, Wang Y, Hagg S, Jylhava J. Frailty and comorbidity in predicting community COVID19 mortality in the UK Biobank: the effect of sampling. medRxiv. 2020:2020.10.22.20217489. doi:https://doi. org/10.1101/2020.10.22.20217489

158. Demombynes G. COVID-19 age-mortality curves are flatter in developing countries: the World Bank. 2020. World Bank Policy Research Working Paper 9313. https://openknowledge.world bank.org/handle/10986/34028
159. Lexmond AS, Nouwen CJA, Fourtassi O, Callan JP. Evolution of COVID-19 cases in selected low- and middle-income countries: have they peaked due to high levels of infection and immunity? medRxiv. 2020:2020.09.26.20201814. doi:https://doi. org/10.1101/2020.09.26.20201814

160. Buss LF, Prete CA, Abrahim CMM, et al. COVID19 herd immunity in the Brazilian Amazon. medRxiv. 2020:2020.09.16.20194787. doi:https://doi. org/10.1101/2020.09.16.20194787

161. Prowse TAA, Purcell T, Baía-da-Silva DC, et al. Inferred resolution through herd immmunity of first COVID-19 wave in Manaus, Brazilian Amazon. medRxiv. 2020:2020.09.25.20201939. doi:https://doi.org/10.1101/2020.09.25.20201939

162. Brazil Ministry of Health. COVID-19 no Brasil, obitos acumulados--Manaus. 2020.

163. Herzog S, Bie JD, Abrams S, et al. Seroprevalence of IgG antibodies against SARS coronavirus 2 in Belgium: a prospective cross-sectional study of residual samples. medRxiv. 2020. https ://doi.org/10.1101/2020.06.08.20125179

164. Pollán M, Pérez-Gómez B, Pastor-Barriuso R, et al. Prevalence of SARS-CoV-2 in Spain (ENE-COVID): a nationwide, population-based seroepidemiological study. Lancet. 2020. https://doi. org/10.1016/s0140-6736(20)31483-5.

165. Stringhini S, Wisniak A, Piumatti G, et al. Seroprevalence of anti-SARS-CoV-2 IgG antibodies in Geneva, Switzerland (SEROCoV-POP): a population-based study. Lancet. 2020;396(10247):313-9. https://doi.org/10.1016/s0140 $-6736(20) 31304-0$.

Publisher's Note Springer Nature remains neutral with regard to jurisdictional claims in published maps and institutional affiliations. 